Children's syntactic-priming magnitude: lexical factors and participant characteristics

Foltz, A.; Thiele, K.; Kahsnitz, D.; Stenneken, P.

\title{
Journal of Child Language
}

DOI:

$10.1017 / S 0305000914000488$

Published: 27/08/2014

Peer reviewed version

Cyswllt i'r cyhoeddiad / Link to publication

Dyfyniad o'r fersiwn a gyhoeddwyd / Citation for published version (APA):

Foltz, A., Thiele, K., Kahsnitz, D., \& Stenneken, P. (2014). Children's syntactic-priming magnitude: lexical factors and participant characteristics. Journal of Child Language, 42(4), 932 945. https://doi.org/10.1017/S0305000914000488

\footnotetext{
Hawliau Cyffredinol / General rights

Copyright and moral rights for the publications made accessible in the public portal are retained by the authors and/or other copyright owners and it is a condition of accessing publications that users recognise and abide by the legal requirements associated with these rights.

- Users may download and print one copy of any publication from the public portal for the purpose of private study or research.

- You may not further distribute the material or use it for any profit-making activity or commercial gain

- You may freely distribute the URL identifying the publication in the public portal ?
}

Take down policy

If you believe that this document breaches copyright please contact us providing details, and we will remove access to the work immediately and investigate your claim. 
Running head: CHILDREN'S SYNTACTIC-PRIMING MAGNITUDE

Children's Syntactic-Priming Magnitude: Lexical Factors and Participant Characteristics

\author{
Anouschka Foltz \\ Bielefeld University \\ Kristina Thiele \\ University of Cologne \\ Dunja Kahsnitz \\ Bielefeld University \\ Prisca Stenneken \\ University of Cologne
}

June 2, 2014

\begin{abstract}
Author Note
Anouschka Foltz, CRC 673 Alignment in Communication, Bielefeld University, CITEC

Center of Excellence Cognitive Interaction Technology, Bielefeld University, and Clinical Linguistics, Faculty of Linguistics and Literary Studies, Bielefeld University; Kristina Thiele, Faculty of Human Sciences, Department of Special Education and Rehabilitation, University of Cologne, CRC 673 Alignment in Communication, Bielefeld University, and CITEC Center of Excellence Cognitive Interaction Technology, Bielefeld University; Dunja Kahsnitz, Clinical Linguistics, Faculty of Linguistics and Literary Studies, Bielefeld University, and CRC 673 Alignment in Communication, Bielefeld University; Prisca Stenneken, Faculty of Human Sciences, Department of Special Education and Rehabilitation, University of Cologne, CRC 673 Alignment in Communication, Bielefeld University, and CITEC Center of Excellence Cognitive Interaction Technology, Bielefeld University; Correspondence
\end{abstract}


concerning this article should be addressed to Anouschka Foltz, CITEC Center of Excellence Cognitive Interaction Technology, Emergentist Semantics Group, P.O. Box 1001 31, 33501 Bielefeld, Germany. Tel.: +49 (0) 521106 12125, Fax: +49 (0) 52110615 12239. E-mail address: anouschka.foltz@uni-bielefeld.de.

Parts of this research have been presented at the $17^{\text {th }}$ Meeting of the European Society for Cognitive Psychology, San Sebastian, Spain, and at the 2011 Annual Meeting of the German Association of Academic Speech and Language Therapists, Munich, Germany. We would like to thank the children and their families for their participation. In addition, we would like to thank Kathryn Bock and three anonymous reviewers for helpful comments on earlier drafts of the paper. 


\section{Abstract}

This study examines whether lexical repetition, syntactic skills, and working memory (WM) affect children's syntactic-priming behavior, i.e. their tendency to adopt previouslyencountered syntactic structures. Children with Specific Language Impairment (SLI) and typically-developing (TD) children were primed with prenominal (e.g., the yellow cup) or relative-clause (RC; e.g., the cup that is yellow) structures with or without lexical overlap and performed additional tests of productive syntactic skills and WM capacity. Results revealed a reliable syntactic-priming effect without lexical boost in both groups: SLI and TD children produced more RCs following RC primes than following prenominal primes. Grammaticality requirements influenced RC productions in that SLI children produced fewer grammatical RCs than TD children. Of the additional measures, WM positively affected how frequently children produced dispreferred RC structures, but productive syntactic skills had no effect. The results support an implicit-learning account of syntactic priming and emphasize the importance of WM in syntactic priming tasks.

keywords: syntactic priming, lexical boost, working memory, productive syntactic skills, specific language impairment 
Children's Syntactic-Priming Magnitude: Lexical Factors and Participant Characteristics

\section{Introduction}

Syntactic priming in sentence production refers to the tendency to repeat previouslyencountered syntactic structures (Bock, 1986). For example, when someone describes a picture of a yellow cup as the cup that is yellow (prime), the interlocutor may describe a picture of a red ball as the ball that is red (target) rather than as the red ball. A syntacticpriming effect occurs when people use a syntactic structure more frequently when primed with that structure compared to when not primed or when primed with an alternative structure. A large adult syntactic-priming literature investigates the syntactic processes underlying such priming effects (e.g. Bock \& Griffin, 2000; Cleland \& Pickering, 2003, see Pickering \& Ferreira, 2008, for a review).

Recently, syntactic priming has gained popularity as a research tool in studies with young children, mainly to gain insight into the nature of children's syntactic representations. Early studies have investigated at what age children show a reliable syntactic-priming effect without lexical overlap, i.e. without repeated open-class lexical items between prime and target, as in the example above (e.g. Huttenlocher, Vasilyeva, \& Shimpi, 2004; Shimpi, Gámez, Huttenlocher, \& Vasilyeva, 2007). Such syntactic-priming effects indicate the presence of underlying abstract rather than lexically-based syntactic representations and are typically observed in children three years and older (e.g. Branigan, McLean, \& Jones, 2005; Messenger, Branigan, \& McLean, 2011; Shimpi et al. 2007, but see Savage, Lieven, Theakston, \& Tomasello, 2003).

The magnitude of the observed syntactic-priming effect has recently received attention in studies with children (e.g. Branigan et al., 2005; Kidd, 2011; Messenger et al., 2011; Rowland, Chang, Ambridge, Pine, \& Lieven, 2012). For example, lexical choices may affect syntactic-priming magnitude. Recent studies have compared trials without lexical 
overlap to those with lexical overlap, i.e. where nouns or verbs repeat between prime and target, e.g. the ball that is yellow followed by the ball that is red (where ball repeats). Adults typically display a so-called lexical boost, such that trials with lexical overlap elicit greater syntactic-priming magnitude than trials without lexical overlap (e.g. Cleland \& Pickering, 2003). Residual-activation (e.g. Cleland \& Pickering, 2003) and implicit-learning (e.g. Chang, Dell, \& Bock, 2006) models propose different underlying mechanisms for the lexical boost. In a residual-activation model, syntactic priming occurs because the primed syntactic structure remains activated and is thus more available during production than the alternative syntactic structure. The nodes of lexical items repeated between prime and target provide additional residual activation and thus further increase the availability of the primed syntactic structure, yielding a lexical boost. Since the same priming mechanisms are assumed for children, they should also show a lexical boost. According to an implicit-learning model, however, different mechanisms underlie the syntactic-priming effect and the lexical boost. Syntactic priming results from long-term changes of connectionist weights: Each primed structure adjusts the weights so as to increase the likelihood that this structure will be used. In contrast, the lexical boost rests on short-term activation of explicit memory traces, which are difficult for children to form, store, and retrieve. This model would thus predict no lexical boost in children (see Rowland et al., 2012, for a detailed explanation of these predictions). Current evidence for a lexical boost in children is mixed: Whereas Branigan et al. (2005) found a lexical boost in three- and four-year-old children, Rowland et al. (2012) did not. Participant characteristics may also affect syntactic-priming magnitude. Recent studies have investigated which linguistic and cognitive abilities may affect children's syntactic-priming behavior (e.g. Kidd, 2011; 2012; Messenger et al., 2011). Teasing apart these factors can specify the kinds of knowledge and resources children draw on in a syntactic-priming task. Again, the few available results have been mixed. For example, 
Kidd's (2011) data revealed a positive correlation between vocabulary size and primed passive productions, but Messenger et al. (2011) found no such effect.

Two factors seem particularly relevant in the context of syntactic priming in production: productive syntactic skills and WM capacity. A productive syntactic task captures production operations similar to those that occur during the priming task (cf. Miller \& Deevy, 2006). Additionally, children with weak syntactic skills may have difficulty accessing abstract representations (cf. Shimpi et al., 2007), especially of more complex syntactic structures (e.g. the ball that is red). Instead, they may choose a simpler structure (e.g. the red ball). Thus, productive syntactic skills may affect children's responses in a syntactic-priming task.

The syntactic-priming task also taxes WM capacity since children must hold the relevant syntactic structure above threshold activation during production (Cleland \& Pickering, 2003) or retain it as a precondition for syntactic priming (Chang et al., 2006). Children with low WM capacity may not be able to keep activated or retain moderately complex syntactic structures and may again resort to simpler structures. Thus, WM capacity may influence children's syntactic-priming behavior.

To our knowledge, no previous study has investigated how separate measures of productive syntactic skills and WM capacity affect children's productions in a syntacticpriming task. However, one study has indirectly addressed these skills: Miller \& Deevy (2006) used a syntactic-priming task with SLI and TD children. SLI children typically have substantial language impairments, especially in the morpho-syntactic domain, despite normal hearing and nonverbal IQ (cf. Miller \& Deevy, 2006). In addition, they typically display WM deficits (e.g., Archibald \& Gathercole, 2006). If both productive syntactic skills and WM capacity positively contribute to syntactic-priming magnitude, SLI children should show weaker syntactic-priming effects than age-matched TD children. Surprisingly, Miller \& 
Deevy (2006) found no difference in syntactic-priming magnitude between SLI and TD children. However, their experimental context posed very small demands on syntactic skills: Children were primed with simple, early-acquired transitive and intransitive structures (e.g. the horse is eating (hay)) and repeated the experimenter's prime sentence before producing the target sentence. Children were also primed in blocks in which they received concentrated input of one syntactic alternative. The experimental context may thus have allowed SLI children to perform at ceiling despite syntactic deficits.

To paint a clearer picture of syntactic-priming magnitude, this study investigates whether four- and five-year-old children show a lexical boost, whether SLI children display a smaller syntactic-priming magnitude than TD children, and whether separate measures of syntactic productive skills and WM capacity affect syntactic-priming behavior. German fourand five-year-old children with and without SLI performed a syntactic-priming task including trials with and without lexical overlap. The task moderately taxed syntactic skills and WM capacity: Prime structures were simple prenominal structures (e.g. the yellow cup) and, importantly, more complex RC structures (e.g. the cup that is yellow). Prime structures were alternated rather than blocked, and children did to repeat the experimenter's prime sentences. Finally, children performed separate tests of productive syntactic skills and WM capacity. Results from this study regarding a lexical boost contribute to the debate concerning the mechanisms behind the syntactic-priming effect. In addition, we hope to identify skills that are involved in the syntactic-priming process.

\section{Methods}

\section{Participants}

Sixteen native German-speaking children were included in the study: Eight children with SLI ( 6 male, aged $4 ; 0$ to $5 ; 9$ years, mean $=4 ; 10, s d=0 ; 7)$ were matched on age $(+/-3$ 
months) to eight TD children ( 5 male, aged 4;2 to 5;7 years, mean $=4 ; 10$, sd $=0 ; 6$ ). General inclusion criteria were normal vision and hearing as well as no known sensory, neurological, emotional, or cognitive impairments. In addition, a sentence-repetition task, where children repeated sentences like the ball that is red produced by the experimenter, confirmed that all children could produce the RC structures required in the experimental task.

Additional inclusion criteria for the SLI group were an independent, previous clinical diagnosis of SLI by a speech-language pathologist and confirmation of this diagnosis by a standardized and norm-referenced test battery. German-language diagnostic materials typically provide a profile rather than explicitly classifying children as SLI or TD (Rosenfeld, Wohlleben, \& Gross, 2008). We therefore used the standardized and norm-referenced Sprachentwicklungstest für drei- bis fünfjährige Kinder (SETK 3-5; Grimm, Aktas, \& Frevert, 2001) and adopted diagnostic criteria informed by Hecking \& Schlesiger (2010) and Keilmann, Moein \& Schöler (2012): Children were included in the SLI group if they performed more than one standard deviation below the norm for their age (i.e. scored $<40$, a typical cut-off in clinical practice, see Rosenfeld, Wohlleben, \& Gross, 2005) in either the sentence comprehension or morphological rule formation subtests of the SETK 3-5. These subtests are most relevant for a study concerned with (morpho-)syntactic skills. Additionally, they seem best suited to detect children with SLI: In a study with 201 children with and without language impairment, no TD child scored lower than 40 in these two subtests (Keilmann et al., 2012). The age-matched TD children had no previous diagnosis of SLI and scored above 40 in all SETK 3-5 subtests. Average subtest scores for both groups and t-tests revealed that the two groups are clearly distinct (see Table 1).

(insert Table 1 about here) 


\section{Materials and Procedure}

Priming Experiment. We used a dialog comprehension-to-production paradigm:

Children took turns with the experimenter describing pictures of colored object drawings, e.g. a red ball. On average, object names were part of the active vocabulary of $74.2 \%(s d=14.7)$ of normally-developing two-year-olds (Grimm \& Doil, 2006; ELFRA II), and thus actively used by children much younger than those included in the study. There were 20 experimental trials: 10 trials with lexical overlap, where the experimenter's prime card and the children's target card showed the same object in different colors (e.g. yellow ball - red ball), and 10 trials without lexical overlap between prime and target (e.g. yellow cup - red ball). To avoid lexical overlap even of closed-class items (i.e. articles and relative pronouns) in the nolexical-overlap condition, prime and target objects had different grammatical genders. In addition, there were 15 filler trials, 10 with prime and target objects sharing color or grammatical gender and 5 with matching prime and target objects. During each trial, the experimenter turned over and described the prime card, using either a simple prenominal structure (10 trials, 5 per overlap condition, e.g. der gelbe Ball 'the yellow ball') or a more complex RC structure (10 trials, 5 per overlap condition, e.g. der Ball, der gelb ist 'the ball that's yellow'). No more than two consecutive primes had the same syntactic structure. Then the child described the target card. All children experienced the same order of pictures and the same syntactic constructions for all prime sentences to ensure comparability across participants. Additional instructions characterized the task as a game: If prime and target cards matched, whoever first rang a provided bell received the cards. The person receiving the most cards won the game. Each session was digitally recorded and later transcribed.

Productive Syntactic Skills. We measured children's productive syntactic skills using the sentence production with situation pictures subtest of the Patholinguistische Diagnostik bei Sprachentwicklungsstörungen (PDSS; Kauschke \& Siegmüller, 2010): Children described 
nine cards depicting different events. As a measure of syntactic skills, we coded the complexity of children's syntactic structures: Children received one point for one-constituent utterances, two points for two-constituent utterances, three points for three-or-moreconstituent utterances, four points for main clauses, and five points for subordinate clauses.

Working Memory. We assessed WM capacity using the memory for number sequences subtest of the Psycholinguistische Entwicklungstest (PET; Angermaier, 1977): Children repeated number sequences increasing in length from two to eight numbers, presented with a speed of two numbers per second. Children received two points for repeating a number sequence correctly on the first try, one point for repeating it correctly only on the second try. The test was stopped if the child failed to repeat a number sequence on both attempts.

Children performed all of the above tasks in three sessions covering no more than four weeks (Session 1: subtests of SETK 3-5 and PDSS; Session 2: priming experiment; Session 3: subtest of PET and sentence-repetition task).

Response Coding. Three coders classified children's responses as prenominal, $\mathrm{RC}$, or other. Unclear cases were discussed until all coders agreed. Prenominal responses required an inflected, attributive adjective followed by a noun, e.g. der rote Ball ('the red ball'). RC responses were coded using a lax and a strict coding scheme (cf. Kidd, 2011; Bencini \& Valian, 2008). The lax coding scheme captured children's general susceptibility to syntactic priming. It therefore allowed two kinds of non-adult-like responses in addition to grammatically correct RC productions, where the noun was followed by a relative pronoun, an uninflected adjective, and a form of to be, e.g. der Ball, der rot ist (literally, 'the ball that red is'). Allowed non-adult-like responses could clearly be identified as attempts to produce RCs and have been reported in the language-acquisition or SLI literature (cf. Brandt, Diessel, \& Tomasello, 2008; Schuele \& Tolbert, 2001): responses where the obligatory relative pronoun was omitted or incorrect, but the verb was in final position, e.g. der Ball, rot ist 
(literally, 'the ball red is') and verb-second RCs, e.g. der Ball, der ist rot (literally, 'the ball that is red') or der Ball, der ist rot ist (literally, 'the ball that is red is'). The strict coding scheme allowed only grammatically correct responses. Both schemes required repetition of the primed noun in the lexical-overlap condition and allowed for small errors in the responses, such as incorrect choice of article or adjective ending. Responses assigned to neither of the above categories were coded as other.

\section{Results}

Priming Experiment. All children were able to perform the experimental task. Children most commonly produced simple prenominal structures $(52.5 \%$ of all children's responses), confirming that these constitute their preferred response. More complex RCs were produced less frequently $(35.6 \%$ and $28.1 \%$ of all children's responses using lax and strict coding, respectively) and were thus dispreferred. We were therefore primarily interested in whether RC primes could prime children to produce these dispreferred and more complex structures.

Lax Coding. We first investigated whether children were susceptible to priming at all, and whether priming susceptibility differed between trials with and without lexical overlap and/or between participant groups. The results are summarized in Figure 1. We fit mixedlogit models (Jaeger, 2008) to the data since they are appropriate for analyzing binomial response variables and allow modeling random participants and items effects within the same analysis. These models require sufficient amounts of data. In particular, they require at least 10 times as many observations of the less frequent kind as predictors in the model (Jaeger, 2011; see Peduzzi, Concato, Kemper, Holford, Feinstein, 1996, for simulations). Of the 320 total observations, 114 were the less frequent RC productions. Thus, despite the seemingly small number of participants, the data contain enough less frequent RC productions to 
warrant models with up to 11 predictors. The initial model included children's responses (RC vs. prenominal/other) as the dependent variable, participant group, prime syntax, lexical overlap, and all interactions as fixed factors, and participants and items as random factors (see Messenger et al., 2011, for comparable analyses and further details). The final statistical model included only prime syntax as a fixed effect (estimate $=2.6985 ; z=8.205 ; p<.001)$ : Children produced reliably more RC responses following RC primes (SLI: 65.0\%; TD: $67.5 \%$ without lexical overlap, $75.0 \%$ with lexical overlap) than following prenominal primes (SLI: 5\% without lexical overlap, none with lexical overlap; TD: $2.5 \%$ without lexical overlap, 5.0\% with lexical overlap). The results demonstrate an overall susceptibility to syntactic priming, irrespective of the presence or absence of a developmental language disorder and not affected by lexical overlap.

(insert Figure 1 about here)

Strict Coding. Next, we tested whether grammatical correctness influenced the experimental results. We therefore performed the same analyses using the strict coding scheme. The results are summarized in Figure 2. Strict coding yielded a total of $90 \mathrm{RC}$ productions, and thus warrants mixed-logit models with up to 9 predictors. The final statistical model included prime syntax (estimate $=3.3694 ; z=6.392 ; p<.001)$ and participant group (estimate $=-1.2674 ; z=-1.967 ; p<.05$ ) as fixed effects. Again, there was a reliable syntactic-priming effect: Children again produced reliably more RC responses following RC primes (SLI: 37.5\% without lexical overlap, $42.5 \%$ with lexical overlap; TD: $62.5 \%$ without lexical overlap, $75.0 \%$ with lexical overlap) than following prenominal primes (SLI: none; TD: $2.5 \%$ without lexical overlap, $5.0 \%$ with lexical overlap). In addition, there was a main effect of group such that SLI children produced fewer RCs (none when not primed and $37.5 \%$ to $42.5 \%$ when primed $)$ than TD children $(2.5 \%$ to $5.0 \%$ when not primed and $62.5 \%$ to $75.0 \%$ when primed). 
(insert Figure 2 about here)

Additional analyses. To further explore whether productive syntactic skills or WM capacity affected syntactic-priming behavior, we performed additional analyses. These analyses refer to the lax coding scheme only. The main effect of group with the strict coding scheme warrants separate analyses for each participant group, which the small number of RC responses per group $(\mathrm{TD}=58$ and $\mathrm{SLI}=32)$ precludes.

Note that SLI children performed reliably worse than TD children both in productive syntactic skills (PDSS subtest; TD: mean $=53.13$, $s d=9.95$, range: 40 to 67; SLI: mean $=$ $37.50, s d=12.75$, range: 11 to $52 ; t=-2.56, p<.05)$ and WM capacity (PET subtest; TD: mean $=15.75, s d=4.63$, range: 9 to 24 ; SLI: mean $=10.13, s d=4.58$, range: 2 to $17 ; t=-$ $2.29, p<.05)$. However, since the groups' score ranges overlap considerably, productive syntactic skills and/or WM capacity may affect children's syntactic-priming behavior, even though the groups did not differ in syntactic-priming magnitude using the lax coding scheme.

To test whether productive syntactic skills or WM capacity may affect children's syntactic-priming behavior, we added the centered raw scores from both subtests as fixed effects to the final statistical model obtained above for the lax coding scheme. Adding these fixed effects to the initial model instead obtained the same results. The condition number $\kappa=$ 2.36 shows that the centered raw scores were not collinear (Belsley, Kuh, \& Welsch, 1980). The final statistical model included both prime syntax (estimate $=2.6726 ; z=8.253 ; p<$ $.001)$ and WM capacity (estimate $=0.8176 ; z=2.304 ; p<.05$ ) as fixed effects. Thus, in addition to the reliable syntactic-priming effect, we found an effect of WM capacity, but not of productive syntactic skills. In particular, the higher the children's WM capacity, the more RCs they produced. 


\section{Discussion}

This study investigated the syntactic-priming behavior of SLI and TD children, using prime-target pairs both with and without lexical overlap. Regardless of coding scheme, the present group of children aged four and five showed a rather strong and reliable syntacticpriming effect.

Using a lax coding scheme that captured children's susceptibility to syntactic priming, i.e. all attempts to produce RCs, we found no difference in priming magnitude between SLI and TD children. This finding, while contrary to our predictions, is in line with Miller \& Deevy (2006), who primed children with simple syntactic alternatives and found similar priming magnitudes in SLI and TD children. Thus, even when primed with moderately challenging syntactic alternatives, as in this study, SLI children are equally susceptible to syntactic priming as TD children.

Using a strict coding scheme, which allowed only grammatically correct RCs, we found that SLI children produced fewer RCs than TD children. While both groups attempted to produce RC structures equally frequently, SLI children produced more grammatical errors than TD children. These results can be interpreted as follows: SLI and TD children may equally frequently access adult-like RC representations and select them for production, but SLI children may generate more errors than TD children in the process from structure selection to production. Thus, SLI children may be impaired in producing, but not in accessing or representing, recently-encountered syntactic structures. Alternatively, some children, and in particular SLI children, may have non-adult-like representations for RC structures, e.g. verb-second structures or structures with omitted relative pronoun. Priming with adult-like RCs may then activate these similar non-adult-like representations and increase their production prevalence (cf. Vasilyeva \& Waterfall, 2012, for evidence that syntactic priming can activate similar, alternative syntactic structures). 
Additional observations from an SLI child who was excluded from the current study because he could not produce RC structures in a sentence-repetition task (cf. general inclusion criteria) support the idea that syntactic priming may activate alternative structures in children. This child produced prenominal structures, e.g. the red ball, when primed with prenominal structures (nine out of ten trials), but predicative structures, e.g. the ball is red, when primed with RC structures (nine out of ten trials). Thus, even though the child produced no RCs, he was clearly sensitive to the priming manipulation.

Confirming results by Rowland et al. (2012), but contrary to Branigan et al. (2005), we found no lexical boost in TD children, regardless of coding scheme. This result is rather surprising since our stimuli are very similar to those used in Branigan et al. (2005). Further studies are needed to explore if and at what age children show a lexical boost. Adding to the literature, we also found no lexical boost in SLI children. Together, these results are inconsistent with accounts that assume the same underlying mechanism for syntactic priming and the lexical boost, e.g. residual-activation accounts. If both phenomena are due to the same mechanism, we should have observed both a priming effect and a lexical boost or, alternatively, no priming effect and no lexical boost. Rather, our results support an implicitlearning account of syntactic priming, where different mechanisms underlie the syntacticpriming effect and the lexical boost. In particular, an implicit-learning account of syntactic priming assumes that the lexical boost rests on explicit memory traces, which are difficult for children to form, store, and retrieve.

While not designed to test predictions about the sources of SLI children's deficit, the lack of a lexical boost also reveals that syntactic deficits in SLI children cannot solely be attributed to absent abstract syntactic representations. If children with SLI had no abstract, but only item-based, syntactic representations, they should have shown a syntactic-priming 
effect only in trials with lexical overlap, but not without lexical overlap. However, SLI children showed reliable and equally strong priming both with and without lexical overlap.

Findings regarding our additional measures showed that WM capacity, but not productive syntactic skills, affected children's syntactic-priming behavior. Our particular syntactic test measured the syntactic complexity of children's picture descriptions. Since our prime alternatives differed (among other things) in syntactic complexity, we considered this factor to be the most relevant aspect of the notion of syntactic skills. Contrary to our predictions, productive syntactic skills as measured by the PDSS subtest did not critically affect how frequently children attempted to produce RCs. However, we cannot rule out that other syntactic skills modulate children's syntactic-priming behavior. In addition, the results from the strict coding revealed that syntactic skills affected whether or not an attempted RC was grammatically correct.

WM capacity influenced children's syntactic-priming behavior in that the higher children's WM capacity, the more RCs they produced. We propose that children with lower WM capacity may not keep a more complex RC structure in WM long enough to reach above-threshold activation or to cause a change in the weight connections between nodes. As a result they produce an RC structure less consistently than children with higher WM capacity and more frequently resort to their preferred syntactic structure, in this case a prenominal structure. Note that our WM task involved sequence memory, which is especially relevant in a syntactic-priming context: It is essential for structure to emerge that can trigger syntactic adaptations in upcoming utterances. In fact, retaining sequences is a prerequisite for syntactic priming to occur in implicit-learning models (cf. Chang et al., 2006). Our data suggest that retaining sequences also modulates how frequently recently-encountered, dispreferred, and more complex syntactic structures are produced. 
In summary, our study supports an implicit-learning model of syntactic priming, underlines the importance of WM functioning in the syntactic-priming process, and suggests that SLI and TD children are equally susceptible to priming, but that SLI children produce fewer adult-like RC structures than TD children. 


\section{References}

Angermaier, M. J. W. (1977). Psycholinguistischer Entwicklungstest (PET). [Test of psycholinguistic abilities.] Weinheim: Beltz.

Archibald, L. M., \& Gathercole, S. E. (2006). Short-term and working memory in specific language impairment. International Journal of Language \& Communication Disorders, 41(6), 675-693.

Belsley, D. A., Kuh, E., \& Welsch, R. E. (1980). Regression Diagnostics, Identifying Influential Data and Sources of Collinearity. New York: Wiley.

Bencini, G. M. L. \& Valian, V. V. (2008). Abstract sentence representations in 3-year-olds: Evidence from language production and comprehension. Journal of Memory and Language, 59, 97-113.

Bock, J. K. (1986). Syntactic persistence in language production. Cognitive Psychology, 18, $355-387$.

Bock, J. K., \& Griffin, Z. M. (2000). The persistence of structural priming: Transient activation or implicit learning? Journal of Experimental Psychology: General, 129(2), $177-192$.

Brandt, S., Diessel, H., \& Tomasello, M. (2008). The acquisition of German relative clauses: A case study. Journal of Child Language, 35, 325-348.

Branigan, H. P., McLean, J. F., \& Jones, M. (2005). A Blue Cat or a Cat that is Blue? Evidence for Abstract Syntax in Young Children's Noun Phrases. In A. Brugos, M.R. Clark-Cotton \& S. Ha (eds.), The Proceedings of the Twenty-ninth Boston University Conference on Language Development (p109-121). Somerville MA: Cascadilla Press.

Chang, F., Dell, G. S., \& Bock, K. (2006). Becoming Syntactic. Psychological Review, 113(2), 234-272. 
Cleland, A. A., \& Pickering, M. J. (2003). The use of lexical and syntactic information in language production: Evidence from the priming of noun-phrase structure. Journal of Memory and Language, 49, 214-230.

Ferreira, V. S., Bock, J. K., Wilson, M. P., \& Cohen, N. J. (2008). Memory for syntax despite amnesia. Psychological Science, 19, 940-946.

Grimm, H., Aktas, M., \& Frevert S. (2001). SETK 3-5:Sprachentwicklungstest für drei- bis fünfjährige Kinder. [SETK 3-5: Language development test for three- to five-year-old children.] Göttingen: Hogrefe.

Grimm, H., \& Doil, H. (2006). Elternfragebögen zur Früherkennung von Risikokindern 2 (ELFRA II) (2nd ed.). [Parental questionnaire for the early identification of children at risk 2.] Göttingen: Hogrefe.

Hecking, M., \& Schlesiger, C. (2010). Late Bloomer oder Sprachentwicklungsstörung?: Diagnostik und Beratung für Familien mit Late Talkern nach dem Dortmunder Konzept. [Late Bloomer or language impairment? Diagnosis and counseling for families of late talkers following the Dortmunder program.] Forum Logopädie, 24(1), 6-15.

Huttenlocher, J., Vasilyeva, M., \& Shimpi, P. (2004). Syntactic priming in young children. Journal of Memory and Language, 50(2), 182-195.

Jaeger, T. F. (2008). Categorical data analysis: Away from ANOVAs (transformation or not) and towards logit mixed models. Journal of Memory and Language, 59, 434-446.

Jaeger, T.F. (2011). Corpus-based Research on Language Production: Information Density and Reducible Subject Relatives. In E. M. Bender \& J. E. Arnold (eds.), Language From a Cognitive Perspective. Grammar, Usage, and Processing. Studies in Honor of Thomas Wasow (pp. 161-198). CSLI Publications Stanford. 
Kauschke, C., \& Siegmüller, J. (2010). Patholinguistische Diagnostik bei Sprachentwicklungsstörungen (PDSS). [Patholinguistic assessment of developmental language disorders.] München: Elsevier.

Keilmann, A., Moein, G., \& Schöler, H. (2012). Werden mit dem SETK 3-5 klinisch diagnostizierte Sprachentwicklungsstörungen erfasst? [Does the SETK 3-5 detect clinically diagnosed language impairment?] HNO, 60, 63-71.

Kidd, E. (2011). Individual differences in syntactic priming in language acquisition. Applied Psycholinguistics, 22(2), 1-26.

Kidd, E. (2012). Implicit Statistical Learning Is Directly Associated With the Acquisition of Syntax. Developmental Psychology, 48(1), 171-184.

Messenger, K., Branigan, H. P., \& McLean, J. F. (2011). Evidence for (shared) abstract structure underlying children's short and full passives. Cognition, 121, 268-274.

Miller, C. A., \& Deevy, P. (2006). Structural priming in children with and without specific language impairment. Clinical Linguistics \& Phonetics, 20(5), 387-399.

Peduzzi, P., Concato, J. Kemper, E., Holford, T. R., Feinstein, A. R. (1996). A simulation study of the number of events per variable in logistic regression analysis. Journal of Clinical Epidemiology, 49(12), 1373-1379.

Pickering, M. J., \& Ferreira, V. S. (2008). Structural priming: A critical review. Psychological Bulletin, 134(3), 427-459.

Rosenfeld, J., Wohlleben, B., Gross, M. (2008). Diagnostische Genauigkeit des SETK 3-5 zur dichotomen Einschätzung von sprachlichen Leistungen. [Diagnostic accuracy of the SETK 3-5 for a dichotomous classification of language abilities.] Talk presented at the 25. Wissenschaftliche Jahrestagung der Deutschen Gesellschaft für Phoniatrie und Pädaudiologie. Düsseldorf, Germany. 
Rosenfeld, J., Wohlleben, B., Gross, M. (2005). Eine Methode zur Phänotypisierung der spezifischen Sprachentwicklungsstörung bei 4- bis 5-jährigen deutschsprachigen Kindern. [A system for phenotyping specific language impairment in German 4- and 5-year-old children.] Talk presented at the 22. Jahrestagung der Deutschen Gesellschaft für Phoniatrie und Pädaudiologie, 24. Kongress der Union der Europäischen Phoniater. Berlin, Germany.

Rowland, C. F., Chang, F., Ambridge, B., Pine, J. M., \& Lieven, E. V. M. (2012). The development of abstract syntax: Evidence from structural priming and the lexical boost. Cognition, 125(1), 49-63.

Savage, C., Lieven, E. V. M., Theakston, A., \& Tomasello, M. (2003). Testing the abstractness of children's linguistic representations: lexical and structural priming of syntactic constructions in young children. Developmental Science, 6(5), 557-567.

Schuele, C. M., \& Tolbert, L. (2001). Omissions of obligatory relative markers in children with specific language impairment. Clinical Linguistics \& Phonetics, 15(4), 257-274.

Shimpi, P. M., Gámez, P. B., Huttenlocher, J., \& Vasilyeva, M. (2007). Syntactic priming in 3- and 4-year-old children: Evidence for abstract representations of transitive and dative forms. Developmental Psychology, 43(6), 1334-1346.

Vasilyeva, M., \& Waterfall, H. (2012). Beyond syntactic priming: evidence for activation of alternative syntactic structures. Journal of Child Language, 39(2), 258-283. 
Tables

Table 1: Average scores for SLI and TD children in the four subtests of the SETK 3-5 and the results from two-sample t-tests comparing SLI and TD children's scores on each test. The subtests relevant for the SLI inclusion criteria are given in italics.

\begin{tabular}{|c|c|c|c|c|}
\hline Group & $\begin{array}{l}\text { sentence } \\
\text { comprehension }\end{array}$ & $\begin{array}{l}\text { morphological } \\
\text { rule formation }\end{array}$ & $\begin{array}{l}\text { phonological } \\
\text { memory for } \\
\text { nonwords }\end{array}$ & $\begin{array}{l}\text { sentence } \\
\text { memory }\end{array}$ \\
\hline SLI & $\begin{array}{l}35(s d=6.5, \\
\text { range: } 23 \text { to } 43)\end{array}$ & $\begin{array}{l}34.1(s d=7.3, \\
\text { range: } 21 \text { to } 46)\end{array}$ & $\begin{array}{l}35.9(s d=8.3, \\
\text { range: } 23 \text { to } 49)\end{array}$ & $\begin{array}{l}33.3(s d=8.3, \\
\text { range: } 18 \text { to } 42)\end{array}$ \\
\hline TD & $\begin{array}{l}56(s d=8.8, \\
\text { range: } 46 \text { to } 74)\end{array}$ & $\begin{array}{l}57.5(s d=6.6, \\
\text { range: } 47 \text { to } 66)\end{array}$ & $\begin{array}{l}46.6(s d=4.8, \\
\text { range: } 40 \text { to } 52)\end{array}$ & $\begin{array}{l}53(s d=9.6, \\
\text { range: } 44 \text { to } 68)\end{array}$ \\
\hline $\begin{array}{l}\text { two-sample t- } \\
\text { test comparing } \\
\text { SLI and TD }\end{array}$ & $\begin{array}{l}t=29.64 \\
p<.0001\end{array}$ & $\begin{array}{l}t=36.77 \\
p<.0001\end{array}$ & $\begin{array}{l}t=17.39 \\
p<.0001\end{array}$ & $\begin{array}{l}t=24.11 \\
p<.0001\end{array}$ \\
\hline
\end{tabular}


Figures

Figure 1: Percentages of SLI (left) and TD (right) children's responses to prenominal and RC primes with and without lexical overlap using the lax coding scheme. The pertinent RC responses are shown in black. Responses overall: prenominal 52.5\%; RC 35.6\%.

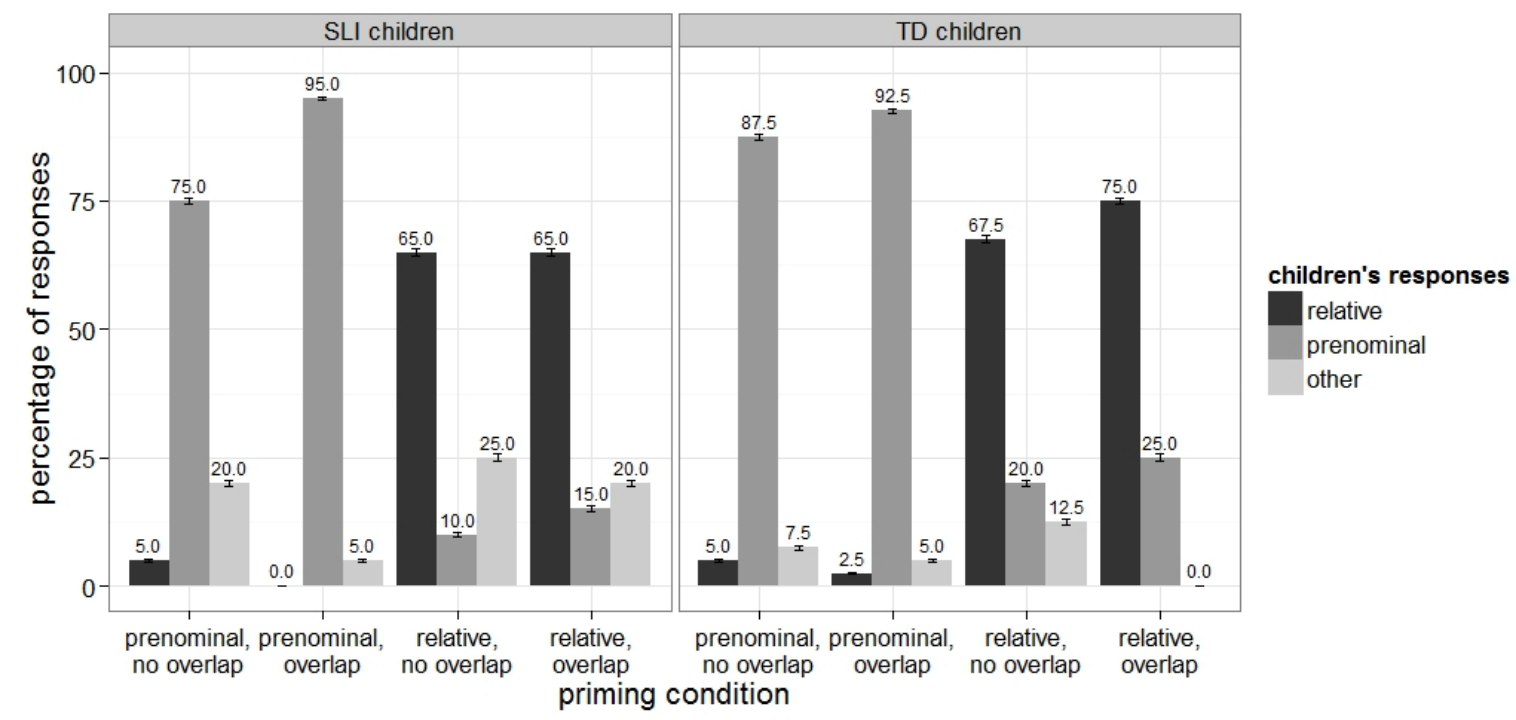

Figure 2: Percentages of SLI (left) and TD (right) children's responses to prenominal and RC primes with and without lexical overlap using the strict coding scheme. The pertinent RC responses are shown in black. Responses overall: prenominal 52.5\%; RC 28.1\%.

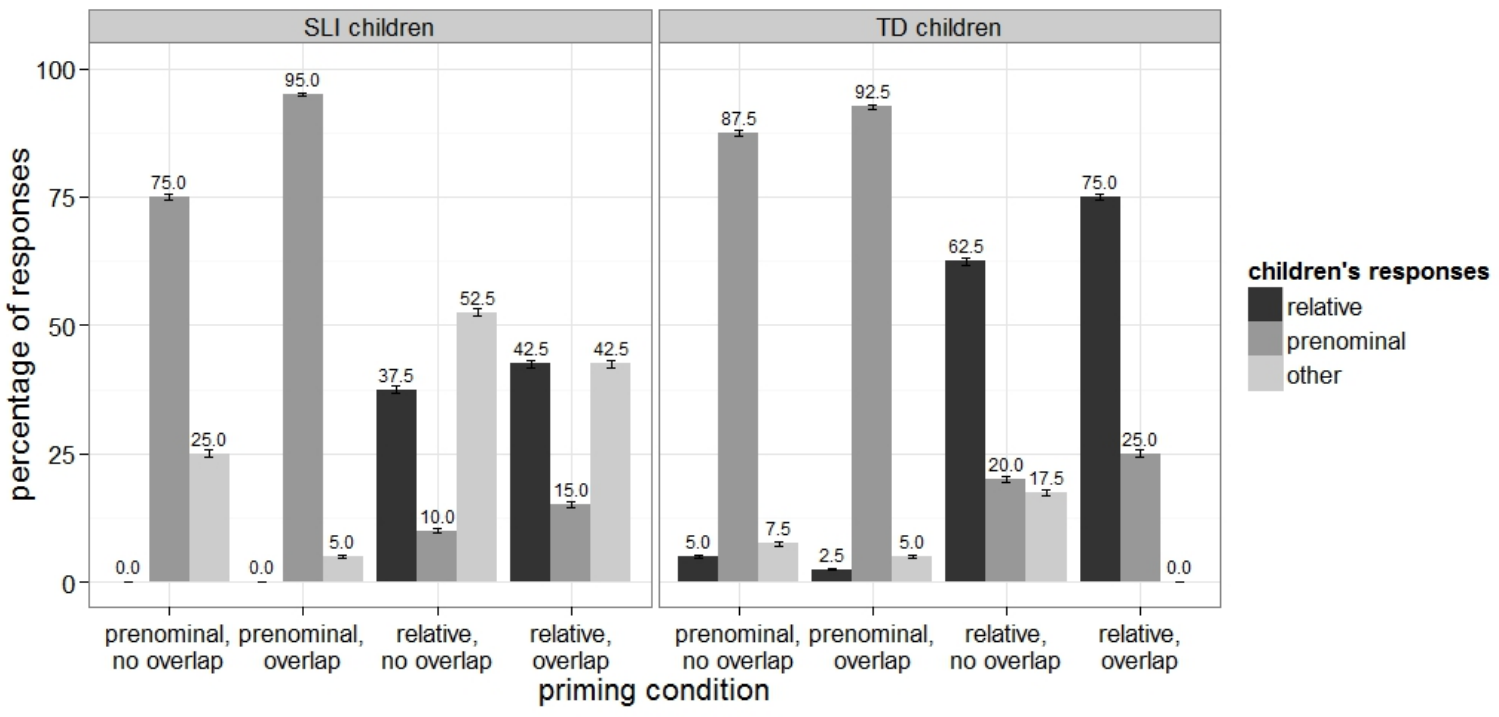

